\title{
TUMOR DE CÉLULAS DE SERTOLI MALIGNO
}

Igor Azurmendi Arín, Roberto Llarena Ibarguren, Jorge García-Olaverri Rodríguez, Ivan Olano Grasa, Emilio Cantón Aller y Carlos Pertusa Peña.

Servicio de Urología. Hospital de Cruces. Bilbao. Vizcaya. España.

Resumen.- OBJETIVO: Aportamos a la literatura un nuevo caso de tumor testicular compuesto por células de Sertoli de características histológicas malignas.

MÉTODOS: Se trata de un varón de 77 años, afecto de un síndrome general constitucional y una masa sólida testicular izquierda en la que tras la orquiectomía se diagnostica de tumor de células de Sertoli maligno, sin diseminación locorregional ni a distancia, con una benigna evolución tras 18 meses de seguimiento.

RESULTADOS: El tumor de células de Sertoli o androblastoma se encuadra en la clasificación de tumores no germinales derivados del estroma de los cordones sexuales. Se

Igor Azurmendi Arin

Apartado de Correos 20134

48080 Bilbao. (España).

igorazurmendi@hotmail.com

O

Trabajo recibido: 26 de noviembre 2007. 
reconocen 3 tipos dependiendo de su composición celular: de célula grande calcificada, de célula esclerosada, y la más frecuente de todas, la variante clásica.

CONCLUSIONES: Siendo el tumor de células de Sertoli un tumor testicular poco común, la forma maligna lo es menos aún, no más del 10\% del total. A pesar de las características patológicas que se relacionan con la malignidad, su comportamiento posterior es imprevisible y poco conocido, al igual que la forma de seguimiento y tratamiento, pues no es sensible a citostáticos. La presencia de metástasis sigue siendo hoy en día el único parámetro válido como valor pronóstico.

Palabras clave: Testículo. Tumor de Sertoli. Androblastoma.

Summary.- OBJECTIVE: We report a new case of Sertoli cell testicular tumor with malignant characteristics.

METHODS: 77-year-old male patient, suffering a general wasting syndrome presenting with a left solid testicular mass with the diagnosis of malignant Sertoli cell tumor after orchyectomy, without local, regional or distant dissemination, and a benign outcome after 18 months of follow-up.

RESUITS: Sertoli cell tumor or androblastoma is classified as non-germ cell tumor derived from the stroma of the sexual cords. There are three types depending on its cellular composition: calcified big cell, sclerotic cell, and the most frequent of all, the classic type.

CONCLUSIONS: Being the Sertoli cell testicular tumor rare, its malignant type is even rarer, accounting for not more than 10\% of all. Despite the pathological characteristics related to malignancy, its posterior behaviour is unpredictable and not much known, the same than follow-up and treatment, because it is not sensible to cytostatic drugs. The existence of metastases continues to be the only valid parameter with prognostic value.

Keywords: Testicle. Sertoli cell tumor. Androblastoma.

\section{INTRODUCCIÓN}

Los tumores de células de Sertoli (TCS) se incluyen junto a los compuestos por células de Leydig, los de la granulosa y los mixtos, dentro de los tumores testiculares no germinales derivados del estroma de los cordones sexuales según la clasificación de 1997 (1), que suponen el $4 \%$ del total de tumores testiculares. Dentro de estos los TCS supondrían cerca del 1\% del total.

Su extremada rareza, unida a la posibilidad, aunque remota, cercana al $10 \%$ de que pueda resultar en un comportamiento maligno, hace del tumor de Sertoli una neoplasia atractiva para su publicación. En una revisión realizada por Pellicé (2) sobre casos publicados en el Estado Español entre 1985 y 2001 encuentra 21 casos, de los que tan solo dos tenían componente maligno. Desde esta fecha han sido escasísimos los nuevos reportes.

\section{CASO CLÍNICO}

Paciente varón de 77 años con múltipes factores cardiopatogénicos, y como único antecedente urológico una hipertrofia benigna de próstata. Es ingresado en el servicio de Medicina Interna para estudio de un cuadro constitucional de 4 meses de evolución con anorexia y pérdida de unos $15 \mathrm{~kg}$ de peso, acompañado de debilidad generalizada y dolor epigástrico cólico de minutos de duración. No contaba otra clínica acompañante. Se realizó un estudio digestivo (gastroscopia, colonoscopia, ecoendoscopia) que fue normal.

La exploración física fue normal, salvo que presentaba un aumento de tamaño de los genitales, por lo que se realizó una ecografía, con el resultado de un hidrocele bilateral, más marcado en el lado izquierdo, con desestructuración de morfología multinodular en el teste izquierdo, que obligaba a descartar proceso maligno subyacente. En la exploración, además de presentar transiluminación positiva bilateral, se palpaba un nódulo duro de $4 \mathrm{~cm}$ localizado en polo superior de teste izquierdo, sugestivo de masa sólida. Las pruebas de imagen a distancia (TAC, RNM) fueron negativos. Se solicitaron marcadores tumorales germinales y LDH, que fueron negativos. Se realizó orquiectomía radical inguinal izquierda.

La descripción macroscópica de la pieza, de unos 9 $\times 6.5 \mathrm{~cm}$, evidenció escaso parénquima testicular sano adyacente al polo superior, en el cual se halló una masa tumoral sólida, multinodular, de coloración blanquecina con algún área marronácea, de $4 \mathrm{~cm}$ diámetro (Figura 1).

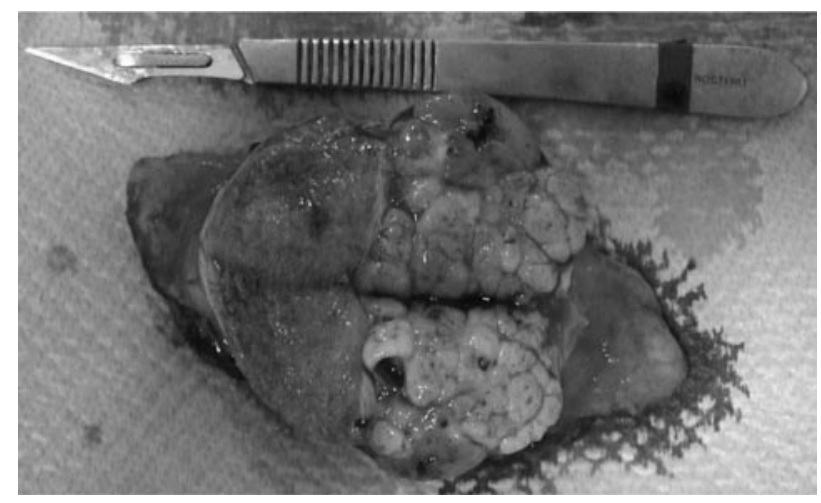

FIGURA 1. Pieza quirúrgica. 
El análisis microscópico mostró áreas de patrón sarcomatoide y crecimiento en sábana junto a áreas donde las células se disponían en un patrón cordonal o formando trabéculas con presencia de estructuras vasculares. Las células eran piramidales, de gran citoplasma, con pleomorfismo nuclear y nucleolos prominentes adquiriendo en zonas un citoplasma muy claro, lipidificado. El índice mitótico era alto, siendo superior a las $5 \mathrm{mi}-$ tosis x10 HPF en las zonas de crecimiento en sábana. La tumoración contactaba con la albugínea e infiltraba el epidídimo sin que prácticamente quedaran túbulos seminíferos viables. Se apreciaban además imágenes muy sugestivas de invasión vascular. En las secciones de parénquima testicular respetado, los túbulos presentaron membrana basal hialinizada, de aspecto atrófico. Las técnicas inmunohistoquimicas evidenciaron positividad para Inhibina, keratina, CK8, CK18, Vimentina, EMA y S-100. El Ki67 mostró positividad intensa en aproximadamente el $30-40 \%$ de las células tumorales. Resultó negativo para Progesterona, PLAP, AFP, HCG, Cromogranina y HMB45.

Con todos estos hallazgos, el diagnóstico fue de tumor de células de Sertoli maligno, con variación de patrones histológicos, clasificado como de tipo Clásico. Doce meses después, persiste aún el cuadro general, que motivó nuevo ingreso en Medicina Interna, sospechándose Enfermedad Inflamatoria Sistémica. Los controles séricos y de imagen en relación al proceso testicular se mantienen dentro de los parámetros normales.

\section{COMENTARIOS}

El TCS fue descrito en 1949 por Telium (3) con el término de "androblastoma", posteriormente pasó a llamarse tumor de células de Sertoli.

Se presenta en cualquier grupo de edad con dos picos de máxima incidencia, en el primer año de vida y entre los 20-45 años $(4,5)$.

En una revisión de 72 casos de Gabrilove y cols. (6) en 1980 , el $37 \%$ se presentaban en la edad pediátrica. Sin embargo, en una revisión de 60 casos de Young de 1998 (7), la mayoría se presentaron con edades comprendidas entre los 15 y 80 años, con una media de 45 años, siendo tan solo 4 , los casos menores de 20 años. Este autor argumentaba que los estudios y series previos incluían tumores de la Granulosa Juvenil dentro de la variante clásica de TCS, de ahí que hubiera casos pediátricos (7).

Se reconoce menor incidencia, similar a los tumores germinales, en la raza negra (4).

Se cree derivado del mesénquima gonadal primitivo (8). Se distinguen 3 tipos de TCS en relación a las varientes celulares:

- de célula grande calcificada,
- de célula esclerosada,

- y la más frecuente de todas, la variante clásica.

Similar a las grandes series $(6,7)$ en los 23 casos recopilados por Pellicé en el Estado Español (2) en un intervalo de 18 años la forma clásica representa el $74 \%$, confirmándose como la más común de todas.

La presentación clínica es común a la de todos los tumores testiculares, presentándose como una masa indolora. Asimismo la exploración y el estudio sonográfico son similares a la de cualquier masa sólida escrotal.

Dado el potencial de síntesis hormonal, tanto de testosterona como de estradiol de la célula de Sertoli, están descritas en un $30 \%$ de los casos manifestaciones endocrinas, siendo la más común de todas en adultos, la ginecomastia, sin olvidar la disfunción eréctil. En el estudio de Young y cols. (7) tan sólo 2 de 60 presentaron crecimiento mamario, padeciendo precisamente estos dos pacientes cirrosis hepática, situación que de por sí cursa con ginecomastia. Nuestro paciente, de 77 años, tampoco presentó manifestación endocrina alguna. En la etapa prepuberal puede producir pubertad precoz en relación al disbalance hormonal que desarrollaría un aumento de estradiol en adultos y un aumento de los niveles plasmáticos de testosterona en niños (5).

Algunas características diferencian los 3 tipos de TCS. Así, los de células grandes calcificadas, más propias de la edad juvenil, se asocian hasta en un $30 \%$ con anomalías hormonales del tipo acromegalia, gigantismo hipofisario, hipercortisolemia, precocidad sexual, pigmentación mucocutánea y síndrome de Peutz-Jeghers (9). Por otro lado esta variante de células grandes calcificadas se asocia a tumores multifocales y bilaterales $(5,7)$, así como con una tendencia moderada hacia el comportamiento maligno.

La variedad esclerosante, es la más infrecuente, de aparición en adultos, de forma unilateral, con muy bajo riesgo de malignidad y sin capacidad para producir manifestaciones endocrinas $(7,9)$. La forma clásica, la más frecuente, aparece como la variante de mayor tendencia a la malignidad, pudiendo presentarse con feminización en adultos hasta en un $25 \%$ de los casos (4).

Varias características patológicas se correlacionan con la malignidad, como son: diámetro tumoral mayor de 5 $\mathrm{cm}$, presencia de necrosis, moderada o severa atípia, invasión vascular e índice mitótico mayor de $5 \times \mathrm{HPF}, \mathrm{y}$ afectación de estructuras vecinas como la albugínea, el epidídimo y el cordón funicular (7).

Aparte de las características histopatológicas malignas, se consideran factores clínicos que ensombrecen el pronóstico, la presentación en la edad adulta junto a ginecomastia, y el gran volumen tumoral $(4,5)$.

En general se considera que el $10 \%$ de los TCS son malignos, aunque el único criterio inequívoco reconocido 
para confirmarlo sea la presencia de metástasis (4). Se ha cifrado en el $50 \%$, los casos de pacientes con TCS maligno que mueren a consecuencia de la presencia de metástasis, retroperitoneales o viscerales.

El tratamiento primario del tumor se realiza mediante orquiectomía inguinal, pudiéndose llegar a plantear cirugía conservadora en los casos bilaterales (10). Se recomienda la linfadenectomía retroperitoneal si se demuestran crecimientos ganglionares en los casos malignos (11) así como radioterapia y poliquimioterapia sistémica, probablemente en un desesperado intento de variar el inexorable pronóstico de los TCS malignos.

El seguimiento periódico y a largo plazo se recomienda ya que se han dado casos de progresión metastásica a largo plazo, incluso a los 15 años (9).

\section{BIBLIOGRAFÍA Y LECTURAS RECOMENDADAS ( ${ }^{*}$ lectura de interés $y^{* *}$ lectura fundamental)}

1. MOSTOFI, F.K.; THEISS, E.A.; ASHELEY, D.J.B.: "Tumors of specializaed gonadal stroma in human male subjects". Cancer, 12: 944, 1959.

**2. PELLICE, C.: "Tumors testiculars de céllules de Sértoli. Sucinta revisió de la literatura i d'autors de 1'Estat Espanyol (periode : 1985-2003)". Annals d' urologia, 5: 2, 2005.

3. TELLIUM, G.: "Estrogen producing Sertoli cell tumor (androblastoma tubulare lipoides) of human testis and ovary; homologous ovarian and testicular tumors III". J. Clinic. Endocr., 9: 301, 1949.

*4. HERNANDEZ, J.E.; ARAMBURU, J.A.; GARCÍAMEDIERO, J.M. y cols.: "Tumor de células de Sertoli esclerosante: Una rara variedad de tumor testicular".

*5. Rev. Urol., 8: 116, 2007.

5. (*) DOMÍNGUEZ, J.F.; VERGARA, E.; FERNÁNDEZ, A. y cols.: "Tumor testicular de células de Sertoli: Variedades clínicas patológicas. A propósito de un caso". Actas Urol. Esp., 21: 519, 1997.

6. GRAVILOVE, J.L.; FREIBERG, E.K.; LEITER, E. y cols.: "Feminizing and non Feminizing Sertoli cell tumors". J. Urol., 124: 757, 1980.

**7. YOUNG, R.H.; KOELLINKER, D.D.; SCULLY, R.E.: "Sertoli cell tumors of the testis, not otherwise specified. A clinicopathologic analysis of 60 cases". Am. J. Surg. Path., 22: 709, 1988.

8. DÍAZ, E.; CALATRAVA, S.; BAEDA, R. y cols.: “Tumor testicular de células de Sertoli. Aportación de un caso". Arch. Esp. Urol., 5: 193, 1997.

9. HITA, E.; LÓPEZ, J.; MELLADO, P. y cols.: "Tumor testicular de células de Sertoli”. Actas Urol. Esp., 25: 74, 2001.

10. GUTIERREZ, J.L.; GARIJO, F.; LADRON, C. y cols.: "Tumor bilateral de células de Sertoli". Arch. Esp. Urol., 40: 523, 1987.

11. DE DIEGO, E.; PASCUAL, C.; PORTILlO, J.A. y cols.: "Tumor testicular de células de Sertoli esclerosante en un paciente VIH". Arch. Esp. Urol., 54: 1129, 2001 . 